\title{
Reversible renal failure due to psychogenic urinary retention
}

\author{
Z. Korzets ${ }^{1}$, R. Garb ${ }^{2}$, S. Lewis ${ }^{3}$ and J.L. Bernheim ${ }^{1}$ \\ Department of 'Nephrology, ${ }^{2}$ Psychiatry and ${ }^{3}$ Medicine "C", Meir General Hospital, Kfar Saba, Sackler School of \\ Medicine, University of Tel-Aviv, Israel.
}

\begin{abstract}
Summary: A case of advanced, reversible renal failure due to psychogenic urinary retention occurring in a 17 year old female, is reported. The diagnosis of psychogenic urinary retention was made on the basis of existent florid psychopathology and the concomitant exclusion of an organic cause. Family psychodynamics are discussed. Psychosocial intervention led to a resumption of normal micturition, the disappearance of the urinary retention with resultant improvement of renal function.
\end{abstract}

\section{Introduction}

Urinary retention, in association with major psychiatric illness such as psychotic states, has long been recognized (Lehman, 1967). Latterly, urinary retention on psychological grounds in patients with less florid psychopathology has been documented (Montague \& Jones, 1979), and authors have referred to urinary retention as an expression of domestic emotional distress (Landau \& Griffiths, 1981).

No published reference has been found to psychogenic urinary retention severe enough to cause gross structural change and consequent renal failure. We would like to report a case that illustrates such a cause and effect relationship.

\section{Case report}

A 17 year old female presented to casualty with a 3 week history of vague upper abdominal pains. No mention was made by the patient of difficulties in urination. She denied any drug ingestion.

She was an attractive, well groomed girl. The only physical finding was a distended urinary bladder palpable up to the umbilicus. Examination per rectum revealed no abnormality. The patient voided urine on request and $200 \mathrm{ml}$ were measured. After voiding, the bladder was clearly still enlarged and she was catheterized. $2000 \mathrm{ml}$ of residual urine were retrieved, after which the catheter was removed. Laboratory data showed a haemoglobin of $10.8 \mathrm{~g} / \mathrm{dl}$ and urea

Correspondence: Z. Korzets, M.B., B.S., Department of Nephrology, Meir General Hospital, Kfar Saba, Israel. Accepted: 21 June 1984
$13.1 \mathrm{mmol} / 1$. Urinary sediment was normal. She was admitted to a general medical ward for further investigation.

The only pertinent past history consisted of a brief hospitalization, at the age of 2 , for a urinary tract infection. Since then, there had been no further episodes of infection or symptoms clearly referrable to the urinary system.

Twenty four $h$ after admission serum creatinine was $327 \mu \mathrm{mol} / 1$. Despite voluntary voiding of $200 \mathrm{ml}$ of urine each time at approximately 4 hourly intervals, within 24 hours she again exhibited a hugely distended bladder. Recatheterization yielded a residual urine volume of $1,700 \mathrm{ml}$, and an indwelling catheter was inserted.

Ultrasound examination of the kidneys revealed bilateral hydronephrosis. This was confirmed by an intravenous urogram (IVU) which demonstrated marked distension of the calyceal system, and ureters (Figure 1). The bladder was enlarged with irregular contours. Retrograde cystography showed no reflux (Figure 2). At cystoscopy a large capacity bladder with some mild trigonitis was seen. Cystometry showed normal contractility with an increased bladder volume.

At this stage, psychiatric consultation was sought. Without medical or surgical intervention, the patient began to void urine spontaneously, allowing the indwelling catheter to be removed on the tenth hospital day. Following removal of the indwelling catheter, daily urine volumes ranged between 1-2 1 , without further evidence of retention. On discharge, 2 weeks later, renal function had improved, serum creatinine being $186 \mu \mathrm{mol} / 1$ and urea $6.1 \mathrm{mmol} / 1$. Two months later on outpatient follow-up serum creatinine had further decreased to $141 \mu \mathrm{mol} / \mathrm{l}$. A follow-up IVU was not obtained. 


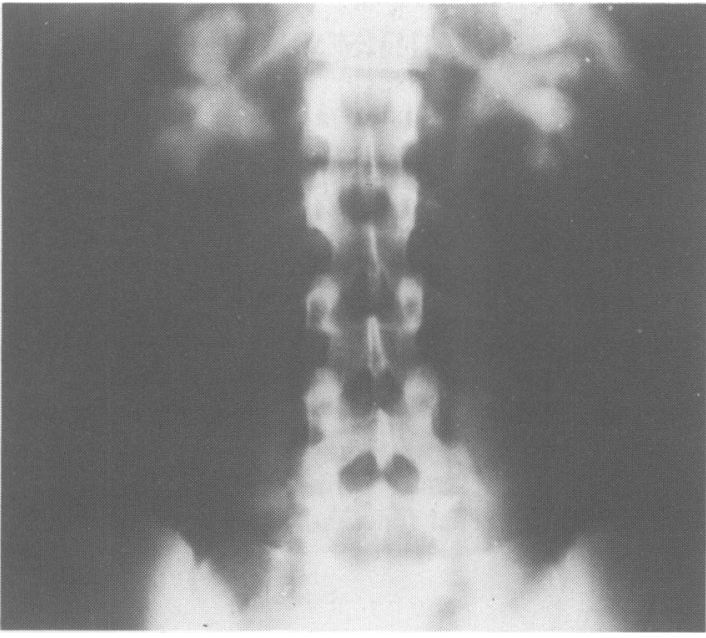

Figure 1 Nephrotomogram showing bilateral dilatation of calcyces, pelvices and ureters.

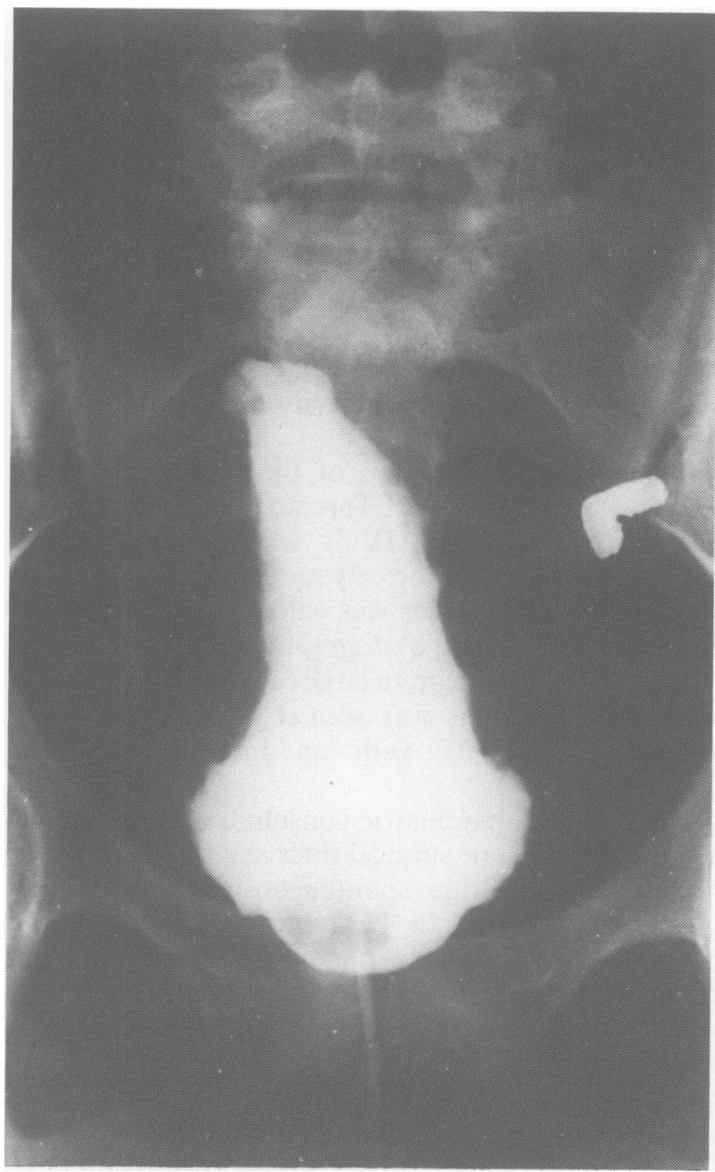

Figure 2 Retrograde cystography - no reflux is evident.

\section{Psychiatric examination}

The patient was interviewed individually as well as conjointly in the presence of her parents. She was an attractive, intelligent young woman, fully orientated $\stackrel{.}{\Rightarrow}$ for time and place. She handled the individual interview in a coquettish way, and seemed at times to be deliberately withholding information. Anxiety was conspicuously absent, and she seemed to actually enjoy the situation. There were no signs of organic brain disorder. No disturbances of thought, and no gross perceptual difficulties were evident. In view of her provocative and disturbing behaviour, together with her striking lack of anxiety (la belle indifference), a primary diagnosis of conversive disorder was entertained. On the other hand, when interviewed conjointly together with her parents the impression was gained of pathological inter-relationships within the family group.

It was evident that the patient dominated both her father and mother, issuing orders which were rapidly complied with, without question. There was an inversion of roles, with the girl assuming a controlling position vis-à-vis her parents. The patient was unable to report accurately on her condition. Symptoms pertaining to her own bodily functions were vague, and this accounted for inconsistencies in the historye taking by various physicians. In this regard, it was striking to note how frequently the mother intervened and actually seemed eager to supply details about hep daughter's most intimate functions. Although this was an acknowledged habitual pattern, the patient expressed extreme resentment to it when this was commented upon. Indeed, there was a pervasive sense of rage and anger, particularly channelled towards the mother. Father was disengaged, sitting throughout the interview in silence. No deference was paid to him. Increasing difficulty in further engaging the family was encountered. The family declined continuing psychiatric enquiry, saying they preferred to pursue this on their own accord. They rather shame-facedly confessed to already having made psycho-therapeutic contact.

\section{Discussion}

Many psychosomatic illnesses have been documented (Lipowski, 1977). Psychogenic aetiology plays a central role in diverse disease states, such as anorexia nervosa, asthma, and hypertension (Landau \& Griffiths, 1981; Hill, 1977). Scattered case reports of urinary retention attributed to various psychological causes have also been described (Montague \& Jones 1979).

Our case involves a young woman, who presented with insidious urinary retention. Residual urine 
volume was as high as 21 . The degree of obstruction was intense and prolonged enough to cause advanced renal failure. The differential diagnoses of obstructive uropathy in this case include: - uretero-vesical reflux, genital herpes simplex, and a neurogenic bladder. Reflux was excluded by a normal retrograde cystogram. In addition, reflux nephropathy with progressive renal failure is usually accompanied by proteinuria (Torres et al., 1980), a feature conspicuously absent in our case. Genital herpes simplex has been infrequently implicated as a cause of urinary retention. This usually occurs in association with a polyradiculitis, confirmed most often by cerebrospinal fluid findings (Caplan et al., 1977). Although no lumbar puncture was performed in this case, careful neurological examination failed to elicit any stigmata of radiculitis. There were no external signs of herpes. Cystometry showed a normally contracting bladder, tending to negate the diagnosis of a neurogenic bladder.

Despite an awareness of the pitfalls of prematurely assigning psychological causation in the paucity of demonstrable organic findings (Kutz et al., in press), we consider our case to represent obstructive uropathy on a psychogenic basis. It is striking that our patient, with no medical or surgical intervention, apart from hospitalization, and minimal psychiatric intervention, spontaneously began voiding urine. Indeed, her renal function had dramatically improved by the time of discharge.

The act of micturition has complex determinants, which include psychological, social and physiological interaction (Godec \& Cass 1981). Only human beings can voluntarily void at any volume in the bladder. In man, a very well documented, cross cultural response to the birth of a sibling is enuresis, as a protest at the new arrival. Urinary retention was a not infrequent cause for evacuation in battle fatigued soldiers (Straub et al., 1949). The outstanding feature of our case is the absence of demonstrable organic cause in the presence of severe psychopathology. When considered out of the context of the family, the patient appeared to be suffering, from a classical hysterical conversion reaction. However, set against the background of her family, it was evident that her condition reflected an ongoing severely dysfunctional family organization. The patterns observed in the cross section of family interaction, included problems of hierarchy, power, and boundary difficulties, leading to enmeshment (Minuchin, 1974). These structural abnormalities were accompanied by rage. The family coping style included the use of denial and mystification. The family system appeared rigid, and fearful of change. These psychodynamic features are accepted criteria of socalled psychosomatic families (Minuchin et al., 1978).

Cases heretofore reported have highlighted some of the features which characterize our case. These include predominant female occurrence, previous psychological difficulties, and marked hostility between daughter and mother. Briquet's syndrome or hysteria as a diagnosis have also been mentioned (Montague \& Jones, 1979). It should be emphasized that while the negative physical and neurological findings reinforced our view, the diagnosis of psychogenic urinary retention was fundamentally based on positive psychiatric signs.

One may speculate as to why the urinary system was chosen as this patient's symptom. Possibly the hospital admission for urinary tract investigation, in a strange environment at a critical age $(2 \mathrm{y})$, was traumatic enough to establish a predetermined model for the patient and her parents. This case outlines the progression of gross family disturbance to psychogenic urinary retention and consequent advanced obstructive uropathy. Indeed, it may be argued that it represents the reversal of renal failure by psycho-social intervention.

\section{Acknowledgement}

Our thanks to Dr M. Aronheim, Consultant Urologist, Meir General Hospital, Kfar Saba, who conducted the urological investigations.

\section{References}

CAPLAN, L.R., KLEEMAN, F.J. \& BERG, S. (1977). Urinary retention probably secondary to herpes genitalis. New England Journal of Medicine, 297, 920.

GODEC, C.J. \& CASS, A.S. (1981). Psychosocial aspects of micturition. Urology, 17, 332.

HILL, O. (1977). The psychological management of psychosomatic diseases. British Journal of Psychiatry, 131, 113.
KUTZ, I., GARB, R. \& KORITSKY, A. The diagnosis of misdiagnosis. Gen. Hosp. Psych. (in press).

LANDAU, J. \& GRIFFITHS, J.A. (1981). Female bladder problems: a case for psychotherapy? South African Medical Journal, 59, 986.

LEHMAN, H.E. (1967). Schizophrenia - Clinical features. In Comprehensive Text Book of Psychiatry, Freedman, A.M., Kaplan, H.I. (eds.). Williams and Wilkes: Baltimore. 
LIPOWSKI, Z.J. (1977). Psychosomatic medicine in the seventies: an overview. Americal Journal of Psychiatry, 134, 233. MINUCHIN, S. (1974). In Families and Family Therapy. Harvard University Press: Cambridge, Mass.

MINUCHIN, S., ROSMAN, B.L. \& BAKER, L. (1978). The psychosomatic family. In Psychosomatic Families. (p. 23.) Harvard University Press: Cambridge, Mass.

MONTAGUE, D.K. \& JONES, L.R. (1979). Psychogenic urinary retention. Urology, 13, 30.
STRAUB, L.B., RIPLEY, H.S. \& WOLF, S. (1949). An experimental approach to the psychosomatic bladder disorders. New York State Journal of Medicine, 49, 635.

TORRES, V.E., VELOSA, J.A., HOLLEY, K.E. (1980). The progression of vesicureteral reflux nephropathy. Annals of $\underset{.}{\stackrel{.}{.}}$ Internal Medicine, 92, 776. 